\title{
Adult mood disorders and childhood
}

psychological trauma

\author{
Transtornos do humor no adulto e trauma \\ psicológíco na infância
}

\author{
Maria Lucrécia Scherer Zavaschi, ${ }^{1}$ Maria Elisa Graeff, ${ }^{1}$ Marcos Tatit Menegassi, ${ }^{1}$ \\ Victor Mardini, ${ }^{1}$ Denise Winkler Simões Pires, ${ }^{1}$ Rafael Homem de Carvalho, ${ }^{2}$ \\ Luis Augusto Rohde, ${ }^{1}$ Cláudio Laks Eizirik ${ }^{3}$
}

\begin{abstract}
Objective: To evaluate the association between adult mood disorders and childhood psychological trauma in a developing country. Method: Adults with and without mood disorders were assessed in a case-control study using the Mini International Neuropsychiatric Interview. Assessment of childhood trauma included physical and sexual abuse, frequent exposure to violence, and parental loss. Results: In two independent multivariate analyses, after adjusting for potential confounding factors, we found a higher odds ratio for frequent exposure to violence in the community ( $p=.037$ ) and for physical abuse by parents or caregivers during childhood/adolescence $(p=.012)$ in the group with mood disorders than in the control group. In secondary analyses splitting the mood disorder group in two subgroups (manic episode, and major depressive episodes/ dysthymia), only manic patients showed significantly higher rates of frequent exposure to violence in the community $(p=0.01)$ and physical abuse during childhood ( $p=0.02$ ) than did patients in the control group. In addition, maniac patients had significantly higher rates of sexual abuse than did controls ( $p=.03$ ). Conclusions: Our findings document an association between violence during childhood and adult mood disorders, especially for manic patients, in a developing country.
\end{abstract}

Keywords: Mood disorders; Mental disorders; Psychotic disorders; Parent-child relations; Child abuse/sexual

Resumo

Objetivo: Avaliar a associação entre transtornos de humor no adulto e trauma psicológico na infância em um país em desenvolvimento. Método: Adultos com e sem transtorno de humor foram avaliados em um estudo de caso-controle utilizando a Mini Entrevista Neuropsiquiátrica Internacional. A avaliação de trauma infantil incluiu abuso físico e sexual, exposição freqüente à violência e perda dos pais. Resultados: Em duas análises multivariadas independentes, após o ajuste para fatores potenciais de confusão, encontramos uma razão de chance mais alta de exposição freqüente à violência na comunidade $(p=0,037)$ e de abuso físico por pais ou cuidadores durante a infância/adolescência ( $p=0,012$ ) no grupo com transtorno de humor do que no grupo controle. Em análises secundárias, dividindo-se o grupo com transtorno de humor em dois subgrupos (episódio maníaco e episódios de depressão maior/ distimia), somente pacientes maníacos demonstraram maiores índices de exposição freqüente à violência na comunidade $(p=0,01)$ e abuso físico durante a infância $(p=0,02)$ do que os pacientes no grupo controle. Além disso, os pacientes com mania tinham índices significativamente mais altos de abuso sexual do que os controles ( $p=0,03$ ). Conclusões: Nossos achados documentam uma associação entre violência na infância e transtornos de humor na idade adulta, especialmente em pacientes com mania, em um país em desenvolvimento.

Descritores: Transtornos do humor; Transtornos mentais; Transtornos psicóticos; Relações pais-filhos; Maus-tratos sexuais infantis

1 Division of Child and Adolescent Psychiatry, Department of Psychiatry, Universidade Federal de Rio Grande do Sul (UFRGS), Porto Alegre (RS), Brazil

2 Universidade Luterana Brasileira, Porto Alegre (RS), Brazil

3 Adult Psychiatric Division, Department of Psychiatry, Universidade Federal do Rio Grande do Sul (UFRGS), Porto Alegre (RS), Brazil This work was partially supported by a research fund from Hospital de Clínicas de Porto Alegre.

Correspondence

Maria Lucrécia Scherer Zavaschi

Serviço de Psiquiatria da Infância e Adolescência,

Financing: Fundo de Incentivo a Pesquisa (FIP), Hospital de Clínicas de Porto Alegre

Hospital de Clínicas de Porto Alegre

Rua Ramiro Barcelos, 2350

Conflict of interests: None

90035-003 Porto Alegre, RS, Brazil

Submitted: 23 September 2005

Phone: (55 51) 2101-8294 / 3231-0609 Fax: (+55 51) 2101-8294

Accepted: 17 April 2006

E-mail: zavaschi@terra.com.br 


\section{Introduction}

The prevalence of depression ranges from $4 \%$ to $10 \%$ within the general population worldwide ${ }^{1}$ and this rate is expected to increase over the next twenty years. ${ }^{2}$ The World Health Organization (WHO) ranked depression as the fourth leading cause of Disability-Adjusted Life Years (DALY) lost worldwide. The lifetime rates of bipolar disorder range from 0.4 to $1.6 \%{ }^{1}$ An epidemiological study conducted in several Brazilian cities found rates of depression up to $10.2 \%$, and the prevalence of a category including mania and cyclothymia reached rates of $1 \%$ in Brasília and São Paulo and $4 \%$ in Porto Alegre. ${ }^{3}$

Depression represents one of the best-known psychopathological manifestations associated with childhood traumatic events. ${ }^{4-6}$

Regarding childhood trauma, physical abuse is strongly associated with adult depression. ${ }^{7}$ In a community sample of 8,116 individuals, Levitan et al. found a significant association between a history of physical or sexual abuse in childhood and major depression, followed or not by a manic episode. They also found a strong relationship between childhood physical abuse and mania. ${ }^{8}$ Wise et al. showed, in a casecontrol study, that women who suffered physical abuse during childhood are three times more likely than others to experience depression over their adult life course. ${ }^{9}$

Mood disorders have been strongly associated with childhood sexual abuse in several studies. ${ }^{10-11}$ In a study including 333 cases with bipolar or unipolar diagnoses, Hyun et al. found that a history of abuse, in particular childhood sexual abuse, was significantly more frequent in bipolar than in unipolar adults. ${ }^{12}$ Lifetime prevalence of major depression in women with a history of childhood sexual abuse is three to five times more common than in women without such a history. Moreover, when the rate of depression is controlled for a history of childhood sexual abuse, the classic 2:1 gender difference between females and males disappears. ${ }^{11}$ However, when sexual abuse in childhood is analyzed in the context of other factors such as violence, the association with depression becomes more modest. ${ }^{10}$ Even considering the studies that control for the effect of child physical abuse by parents or caregivers on the association between childhood sexual abuse and depression in adulthood, most of them do not control for the effect of community violence. ${ }^{9}$

Although still rare in the literature, references to developmental and emotional damages caused by exposure to community violence are increasing. ${ }^{10,13}$ Singer et al. ${ }^{14}$ in a sample of 3,735 high school students, using an anonymous self-report questionnaire, found that youths who had witnessed or suffered recent exposure to shooting and knife attack and past exposure to shooting and knife attack were more depressed, aggressive and anxious than other students. In addition, Ward et al. ${ }^{13}$ documented a correlation between exposure to urban violence and symptoms of depression and post-traumatic stress. Of note, however, few studies assessed the impact of exposure to community violence on rates of depression during adulthood controlling for other traumatic childhood events.

Several studies have documented an association between childhood loss events and adult depression. ${ }^{15-16}$ Patten found a significant association between maternal loss before the age of 11 and depression in females in a meta-analysis of the literature. ${ }^{16}$ A large, nationally representative survey of a sample of 13,017 subjects was conducted in the U.S. to assess the consequences of parental absence during childhood. Those separated from one parent during childhood showed a higher score for depression than those raised and continuously cared for by both parents. ${ }^{15}$ However, Mireault and Bond failed to find a significant association between parental loss during childhood and depression in adult life. ${ }^{17}$ In a study including 140 subjects who had lost one parent before the age of 18 and a control group $(n=239)$, no differences regarding anxiety and depression were found.

Given the destructive potential of mood disorders for individuals and for society, it is highly relevant to study the association between childhood trauma and adult mood disorders. However, studies concerning childhood trauma and adult psychopathology are scarce in Latin American countries. ${ }^{3}$ Since it is known that depression is influenced by cultural factors, ${ }^{13,18}$ there is a surprising lack of studies investigating and validating the association of childhood trauma with adult mood disorders in developing countries. Therefore, we aimed to evaluate the association between adult mood disorders and childhood psychological trauma in a sample of outpatients of a Brazilian general hospital. For the purpose of the study, childhood trauma included physical and sexual abuse, exposure to community violence, and loss events. Based on the literature, the authors raised the hypothesis that adults with a mood disorder diagnosis had suffered more childhood psychological traumas than those without such a diagnosis.

\section{Method}

\section{Subjects and sampling}

The sample was drawn from outpatient services at the Clinical Hospital of Porto Alegre (HCPA). This is the school hospital of the Universidade Federal do Rio Grande do Sul (UFRGS), located in Porto Alegre, Brazil. Porto Alegre, with a population of $1,800,000$, is the capital of Brazil's southernmost state.

The test group included male and female adults (ages ranging from 18 to 65) from the Mood Disorders Outpatient Program in the Division of Psychiatry at HCPA, with a lifetime diagnosis of Mood Disorder (Major Depressive Episodes, Manic Episodes, which will place the subject in the bipolar group, and Dysthymia), according to the DSM-IV. ${ }^{19}$ The control group consisted of male and female adult outpatients (ages ranging from 18 to 65) from other non-psychiatric outpatient services at the HCPA, with no diagnosis of mood disorder or any other severe psychiatric mental disorder, such as Schizophrenia or Dementia, at the time of evaluation. Exclusion Criteria for both groups included serious clinical disorders affecting consciousness, and mental retardation (intelligence quotient below 70).

All adults who contacted the Mood Disorders Program between January 2001 and July 2002 were eligible for the study. On the assessment days, there was a random selection among the first three patients on the appointment list of the outpatient service. The selected patients were invited to take part in the study. If one of the patients did not accept to participate, the next patient on the list was invited, and so on. Controls were also randomly selected from clinical outpatient services of the same hospital, during the same period and keeping the same appointment schedule of patients in the Mood Disorders Program with the same systematic. After deciding to be included in the study, all patients from both groups were referred to the Division of Psychiatry and met the interviewers. The purpose of that relocation was to keep the interviewers blind to group status. All patients were instructed not to inform the interviewers in which outpatient services they had been treated before. 
Subjects provided written informed consent. The investigation was approved by the Ethical Committee of the HCPA (approved as an IRB by the Office for Human Research Protections, United States of America - IRB 00000921).

\section{Instruments and procedures}

Demographic data (age, sex, ethnicity, origin, socioeconomic level and religious practice) were obtained through the administration of a questionnaire. The M.I.N.I. (Mini International Neuropsychiatric Interview, Brazilian Version 5.0) and the M.I.N.I. Plus $5.0^{20}$ were used to identify psychiatric disorders. The M.I.N.I. is a standardized, brief, diagnostic interview, compatible with DSM-III-R/IV and ICD-10 criteria. The more detailed version, M.I.N.I. Plus, offers the possibility of reaching the diagnosis of the main psychotic and mood disorders defined in DSM-IV. The M.I.N.I. is already available in approximately 30 languages, including Portuguese. ${ }^{21}$ The reliability and validity of its Brazilian version was assessed in a previous study. ${ }^{21}$ In the present study, the inter-rater reliability of the interviewers (trained psychiatrists) was assessed using diagnostic interviews of eleven patients, each conducted by an experienced psychiatrist extensively trained to apply both M.I.N.I. and M.I.N.I. plus. Kappa coefficients varied from 0.86 to 1.0 , showing excellent agreement. ${ }^{22}$

Intelligence quotient was estimated using the block design and vocabulary subtests of the Wechsler Intelligence Scale for Adults (WAIS-R), ${ }^{23}$ applied by a trained psychologist.

The following events were defined as childhood trauma for the present study:
1) Physical abuse committed by parents, stepparents, adoptive parents, or other caregivers.

2) Child sexual abuse, defined as sexual contact between the patient and father, mother or substitutes, siblings, relatives or non-family members. The following situations were defined as sexual contact: body contact, or inappropriate physical touch administered to subjects during childhood by father, mother or substitutes, siblings, relatives and non-family members.

3) Childhood loss events, concerning the death of one or both biological parents, or one or both non-biological parents, and death of a biological or non-biological sibling.

All these outcomes were evaluated by the Familial Experiences Interview. ${ }^{24}$ That instrument consists of questions about physical and sexual abuse, physical negligence, loss (due to death, divorce or long separation), difficulties in school performance, frequent change of family residence, long periods of parental unemployment, parental mental illness, and other events. Each event was evaluated considering frequency, severity, duration, emotional impact on the patient, age of occurrence, and kind of perpetrator. ${ }^{24}$ In previous studies, this interview offered a good reliability level for the assessment of maltreatment and physical abuse. ${ }^{24}$

4) Exposure community violence, evaluated through Richters and Martinez ${ }^{25}$ Screening Survey of Children's Exposure to Community Violence, modified by Osofsky. ${ }^{26}$ This scale assessed the frequency with which the subjects might have been submitted to different forms of community violence in real life, either having experienced, witnessed or heard about it. Violence included being chased by gangs, exposed to illegal drugs, fights, beatings, aggressions, muggings, accidents,

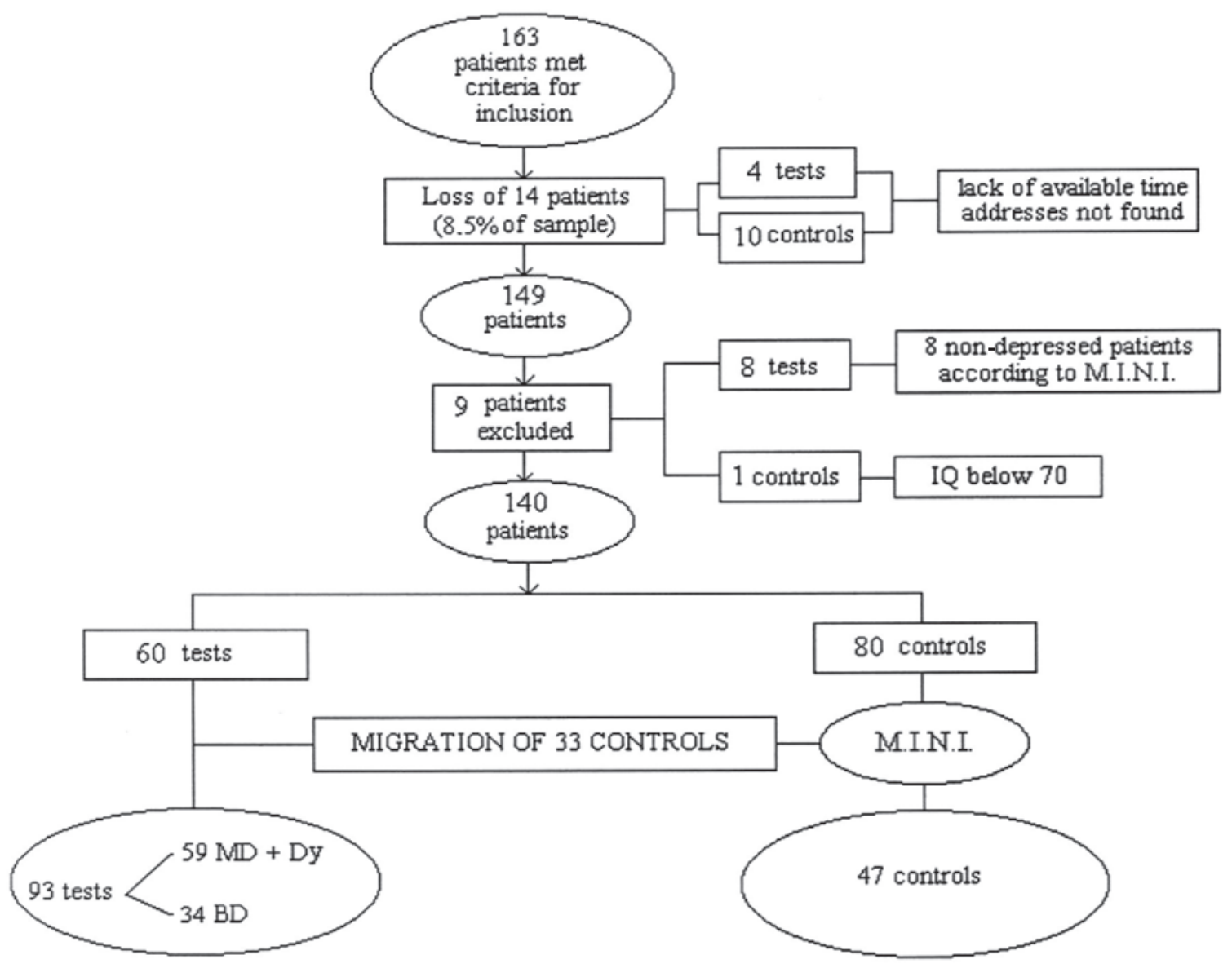

Figure 1 - Flowchart of the Sampling Process 
Table 1 - Demographic variables and parental mental illness in the mood disorder and control groups

\begin{tabular}{|c|c|c|c|}
\hline \multirow[t]{2}{*}{ Variables } & $\begin{array}{c}\text { Mood } \\
\text { disorders }\end{array}$ & Controls & \multirow[t]{2}{*}{ p-value } \\
\hline & $(n=93)$ & $(n=47)$ & \\
\hline \multicolumn{4}{|l|}{ Sex } \\
\hline Female & $89(95.7)$ & $41(87.2)$ & $0.09^{*}$ \\
\hline Age & $46.8 \pm 10.7$ & $45.8 \pm 13.4$ & $0.63^{4}$ \\
\hline Ethnicity & & & $0.56^{\circ}$ \\
\hline Caucasian & $82(88.2)$ & $39(83.0)$ & \\
\hline Marital status & & & $0.02^{\prime \prime}$ \\
\hline Without a partner & $56(60.2)$ & $18(38.3)$ & \\
\hline Occupation & & & $0.18^{\prime \prime}$ \\
\hline $\begin{array}{l}\text { Without income } \\
\text { Education }\end{array}$ & $40(43.0)$ & $14(29.8)$ & $0.91^{*}$ \\
\hline Finished high school & $36(38.7)$ & $17(36.2)$ & 0.91 \\
\hline Some college & 57 (61.3) & $30(63.8)$ & \\
\hline Per capita income & $1.42(0.93 ; 2.29)$ & $1.90(1.14 ; 2.65)$ & $0.10^{\circ}$ \\
\hline Religious practice & & & $0.07^{*}$ \\
\hline Practicing & $55(60.4)$ & $20(42.6)$ & \\
\hline Intelligence quotient (IQ) & & & $0.33^{\forall}$ \\
\hline Borderline (70-79) & $11(11.8)$ & $2(4.3)$ & \\
\hline Bellow-average (80-89) & $53(57.0)$ & $26(55.3)$ & \\
\hline Average $(90-109)$ & $28(30.1)$ & $19(40.4)$ & \\
\hline Bright-normal (> 110) & $1(1.1)$ & $0(0.0)$ & \\
\hline $\begin{array}{l}\text { Parental mental illness } \\
\text { (Ogata et al., 1990) }\end{array}$ & & & $0.001^{\prime \prime}$ \\
\hline Present & $63(68.5)$ & $18(38.3)$ & \\
\hline \multicolumn{4}{|c|}{$\begin{array}{l}\text {-Fisher's exact test } \\
\text { \#Yates's chi-square test } \\
\text { - Pearson's chi-square test } \\
\text { * Presented values as mean } \pm \text { standard deviation Student's } T \text { test } \\
\text { - MW }=\text { Minimum wage }\end{array}$} \\
\hline
\end{tabular}

deaths and murder of relatives or non-relatives. An overall score of exposure to violence excluding the question related to child sexual abuse was considered for each subject. This instrument has been widely employed in studies on community violence in the National Institute of Mental Health (NIMH). ${ }^{27}$

\section{Data analysis}

The data were analyzed by SPSS version 12.0 and PEPI version 3.0. Categorical variables were compared through chisquare test, or Fisher's exact test and partitioned chi-square test when necessary. Continuous variables were compared through Student's t-test (when presenting normal distribution) or Mann-Whitney's $U$ test (when the distribution was asymmetrical).

The control of potential confounding factors was obtained through multivariate logistic regression analyses. All variables showing some level of association in previous dichotomous analyses $(p<0.20)$ were included in those models. All confounding variables that could show collinearity were excluded from these analyses. The level of significance accepted in all analyses was 5\%. The three subgroups (Bipolar disorder, Major Depression and control), were compared by using a one-way analysis of variance (ANOVA) to test association with multiple incidents of community violence. Post hoc tests were done using Tukey's honestly significant difference test.

\section{Results}

The sample comprised 163 patients. Fourteen subjects (10 controls and 4 tests) did not complete the evaluation due to lack of time at that moment. Although the researchers tried to contact all of them once or twice afterwards, none agreed to take part in the study. The loss of the 14 subjects represented a sample loss of $8.5 \%$. Nine of the remaining 149 patients were excluded, eight of the test group and one of the control group. Those patients of the test group were excluded for not presenting depression according to the M.I.N.I., although they had been included in the Mood Disorders Program (subthreshold cases). The patient excluded from control group had an IQ below 70 .

The final sample included 140 patients. Originally, given that the researchers were blind to the different steps of the evaluation, the sample was divided in two groups of subjects: 60 tests and 80 controls. However, 33 of the controls coming from clinics other than the Mood Disorders Program met DSM-IV criteria for Mood disorders, according to the M.I.N.I. and the M.I.N.I. plus. Those 33 patients, originally from the control group, thus migrated to the test group. Therefore, after migration, the sample was comprised of 93 subjects (major depression and dysthymia $\mathrm{n}=59$ and bipolar disorder $n=34)$ in the test group and 47 subjects $(n=47)$ in the control group, as shown in Figure 1.

\section{Demographic characteristics}

Demographic characteristics and history of parental mental illness of the sample after migration are shown in Table 1. No significant differences between the test group and the control group were found concerning sex $(95.67 \%$ and $87.2 \%$ of female subjects, respectively; $p=.086)$, age $(46.8 \pm 10.7$ and $45.8 \pm 13.4$, respectively; $p=.63)$, ethnicity $(88.2 \%$ and $83.0 \%$ of Caucasians, respectively; $p=.56$ ), occupation (43.0\% and $29.8 \%$ unemployed, respectively; $p=.18$ ), education (38.7\% and $36.2 \%$ finished high school, respectively; $p=.91)$, per capita income $(p=.10)$, religious practice $(60.4 \%$ and $42.6 \%$ practicing, respectively; $p=.07$ ) and intelligence quotient $(97.7 \%$ and $96.0 \%$ with average $I Q$, respectively; $p=.33$ ). However, significant differences were found between patients with a mood disorder diagnosis and controls regarding both the lack of a partner $(60.2 \%$ and $38.3 \%$, respectively; $p=.02$ ) and parental mental illness $(68.5 \%$ and $38.3 \%$, respectively; $p=.001)$.

\section{Bivariate analysis}

A significantly larger proportion of patients with a mood disorder diagnosis than patients without that diagnosis had a history of childhood physical abuse by parents or caregivers $(60.2 \%$ vs. 38.3\%) ( $p=.02)$; moreover, a significantly larger proportion of patients with a mood disorder diagnosis than patients without that diagnosis had suffered childhood sexual abuse $(32.3 \%$ vs. $12.8 \%$ ) ( $p=.02$ ). Regarding childhood loss events, no significant difference was found between patients with a mood disorder diagnosis and controls $(41.9 \%$ and $38.3 \%$ of loss events, respectively; $p=.82$ ). Regarding exposure to multiple incidents of community violence, patients with a mood disorder diagnosis had a significantly higher level of exposure to community violence (mean $\pm \mathrm{SD}=12.26 \pm 8.06$ ) than those in the control group (mean $\pm S D=8.63 \pm 7.63$ ) $(p=.012)$ (Figure 2).

\section{Logistic regression analysis}

The three independent factors significantly associated with mood disorders in adulthood in bivariate analysis (physical abuse by parents or caregivers, level of exposure to multiple incidents of community violence and childhood sexual abuse) were controlled for potential confounding factors in a multivariate logistic regression analysis. The confounding factors associated with mood disorders with a $p<0.20$ were 


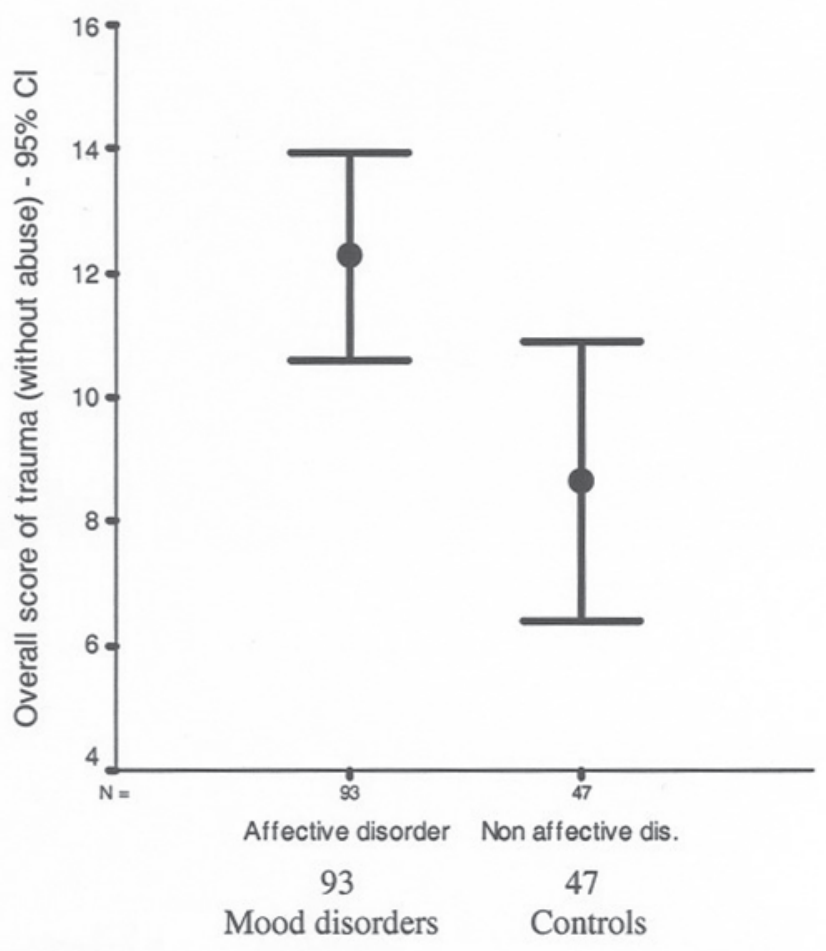

Figure 2 - Mean and $95 \%$ confidence intervals of the overall score of exposure to multiple incidents of community violence between mood disorders patients and controls (Student's t test; $p=0.012$ )

sex, marital status, income, religious practice and parental history of mental illness.

Due to the presence of high collinearity between the factors studied (physical abuse by parents or caregivers, exposure to multiple community incidents of violence, and childhood sexual abuse), the association of each isolated independent variable and mood disorders adjusted for potential confounding factors were assessed in three different models. In the model including a history of physical abuse by parents or caregivers, the association with mood disorders remained significant after the adjustment for confounding factors ( $O R=2.91$; $95 \% \mathrm{Cl}=1.27-6.69 ; \mathrm{p}=.012$ ) (Table 2). In the model including the exposure to multiple incidents of community violence, we were also able to document an association between that variable and mood disorders even after controlling for confounding variables $(\mathrm{OR}=1.06 ; 95 \% \mathrm{Cl}=1.004-1.12 ; \mathrm{p}=.037)$ (Table 3). Unlikely bivariate analysis, sexual abuse was not associated with mood disorders in the multivariate model $(\mathrm{OR}=2.17 ; 95 \% \mathrm{Cl}=0.803-5.863 ; \mathrm{p}=.127)$.

We also performed a multivariate logistic regression analysis including all three factors and adjusting for potential confounding variables. The results of this logistic regression analysis were similar to those found when models were conducted independently. The effect of physical abuse by parents or caregivers remained significant $(\mathrm{OR}=2.816$; $95 \% \mathrm{Cl}=1.202-6.597 ; p=.017$ ) and the effect of the exposure to multiple incidents of community violence was less significant (only a trend was detected) (data not shown, but available upon request).

\section{Subdividing mood disorders}

The comparison between the three groups (Manic episode, Major Depressive episodes and Dysthymia, and Control Group) in relation to the level of exposure to incidents of community violence using the ANOVA test indicated significant difference between the groups ( $F=5.99 ; p=.003)$. The Post hoc analyses (Tukey's test) revealed a significant difference only between the manic episode and the control group $(p<.01)$. In addition, both a history of physical abuse by parents or caregivers and childhood sexual abuse were only significantly more frequent in the group of patients who had a manic episode than in the control group (partitioned Chi-square Test $p=.02$ and $p=.03$, respectively). It is important to note that no significant difference was detected among the manic episode group and the other two groups concerning demographic factors. As expected, the manic episode group presented significantly higher rates of parental mental illness than the control group $(p=.01)$.

\section{Discussion}

In a sample comprising subjects from outpatient services of a University general hospital in Brazil, we were able to document an association between adult mood disorders and childhood psychological trauma. In other words, we found a higher odds ratio for exposure to multiple incidents of community violence and for physical abuse by parents or caregivers during childhood/adolescence in the group with mood disorders than in the control group, when these associations were assessed in the context of several potential confounding variables. Specifically, manic patients were the only group that showed significantly higher rates of exposure to multiple incidents of community violence and childhood physical and sexual abuse than the control group.

In this study, $33(41.3 \%)$ subjects of the control group who met the criteria for mood disorders according to the M.I.N.I. migrated to the test group. This is not an unexpected finding. Similar results were reported either by other researchers ${ }^{28}$ or by investigators in our Hospital who previously documented a prevalence of $40.4 \%$ of depressed patients in non-psychiatric wards. ${ }^{29}$

Table 2 - Bivariate and multiple logistic regression analyses

\begin{tabular}{|c|c|c|c|}
\hline Variable & Global Odds Ratio (95\% $\mathrm{Cl})$ & Adjusted Odds Ratio ( $95 \% \mathrm{Cl}$ ) & p-value* \\
\hline Presence of physical abuse by parents or caregivers & $2.4(1.19 ; 5.01)$ & $2.91(1.27 ; 6.69)$ & 0.012 \\
\hline Sex (female) & $3.3(0.87 ; 12.17)$ & $2.52(0.55 ; 11.64)$ & 0.237 \\
\hline Religious practice (practicing) & $2.1(1.01 ; 4.22)$ & $2.26(0.99 ; 5.13)$ & 0.052 \\
\hline Per capita income & $0.98(0.82 ; 1.17)$ & $0.97(0.79 ; 1.19)$ & 0.779 \\
\hline Marital status (w/o a partner) & $2.4(1.19 ; 5.01)$ & $2.39(1.06 ; 5.36)$ & 0.035 \\
\hline Parental mental illness & $3.5(1.68 ; 7.30)$ & $2.43(1.09 ; 5.45)$ & 0.031 \\
\hline
\end{tabular}

‘Wald's Test - Multiple logistic regression 
Table 3 - Bivariate and multiple logistic regression analyses

\begin{tabular}{|c|c|c|c|}
\hline Variable & Global Odds Ratio ( $95 \% \mathrm{Cl})$ & Adjusted Odds Ratio ( $95 \% \mathrm{Cl})$ & p-value* \\
\hline Exposure to multiple incidents of community violence & $1.1(1.01 ; 1.12)$ & $1.06(1.004 ; 1.12)$ & 0.037 \\
\hline Sex (female) & $3.3(0.87 ; 12.17)$ & $3.26(0.75 ; 14.09)$ & 0.114 \\
\hline Religious practice (practicing) & $2.1(1.01 ; 4.22)$ & $1.95(0.88 ; 4.29)$ & 0.099 \\
\hline Per capita income & $0.98(0.82 ; 1.17)$ & $1.00(0.79 ; 1.25)$ & 0.974 \\
\hline Marital status (w/o a partner) & $2.4(1.19 ; 5.01)$ & $2.58(1.16 ; 5.74)$ & 0.020 \\
\hline Parental mental illness & $3.5(1.68 ; 7.30)$ & $2.53(1.14 ; 5.61)$ & 0.022 \\
\hline
\end{tabular}

- Wald's Test - Multiple logistic regression

Our findings were consistent with those found in the literature regarding the association of childhood psychological trauma with adult mood disorders. ${ }^{6,9}$ However, studies on this relevant association are scarce in Latin American countries. ${ }^{30-31}$ Tognola and $\mathrm{Racz}^{30}$ in a retrospective study with depressed women who reported their childhood history, found that $91.8 \%$ of them had suffered traumatic experiences during childhood.

Our findings suggest that patients with a mood disorder diagnosis show a higher rate of childhood physical abuse by parents than patients without such a diagnosis when potential confounding factors are controlled. Moreover, manic patients seem to be the only subgroup showing a significantly higher rate of childhood physical abuse among patients with mood disorders. These findings are in agreement with data from other studies. ${ }^{7,9,12,31}$ Wise et al. found an association between violent victimization early in life and major depressive disorder in women in a case-control study. ${ }^{9}$ Levitan et al., ${ }^{8}$ and later, Hyun et al., ${ }^{12}$ and Christensen et al., ${ }^{32}$ studied negative life events and rates of physical and sexual abuse in depressive subgroups. Their data suggested that patients with bipolar disorder also reported higher rates of physical abuse than non-bipolar depressive patients. A possible explanation, as noted by Levitan et al., is that impulsive behavior among children who may later become bipolar, result in excessive discipline by caregivers. ${ }^{8}$

Sexual abuse was more prevalent among our patients with a mood disorder diagnosis than among controls in the bivariate analysis. However, when sexual abuse was controlled for confounding variables, the association of childhood sexual abuse with mood disorders in adults did not remain significant. Most previous investigations suggest an association between childhood sexual abuse and depressive symptoms in adult life. ${ }^{6-}$ 7,9 The findings of Benedict et al. however, are similar to ours. ${ }^{10}$ Through bivariate analysis, they have also found an association between childhood sexual abuse and depressive symptoms in women. However, that association became more modest when sexual abuse was adjusted for the impact of other factors. They suggested that negative life events and low socioeconomic level were more strongly associated with adult depression in the women of their sample. According to other investigators, violence added to sexual abuse was more significantly associated with depression than sexual abuse "without violence". Although the reasons for those findings remain unclear, it is important to note that the majority of previous studies suggesting an association between childhood sexual abuse and adult depression did not control for the effect of community violence. The fact that childhood sexual abuse was significantly more frequent in the group of patients who reported manic episodes when compared to the control group is consistent with the findings of Hyun et al. ${ }^{12}$ and Levitan et al. ${ }^{8}$

Our study suggests that patients with a mood disorder diagnosis present a higher rate of exposure to multiple incidents of community violence than patients without such a diagnosis when potential confounding factors are controlled. In addition, manic patients seem to be the only subgroup showing significantly higher rates of exposure to multiple incidents of community violence among patients with mood disorders. To our knowledge, this is the first case-control study specifically designed to assess this association in a developing country. Moreover, our findings demonstrate the importance of analyzing potential intra-familial risk factors in a more comprehensive context in such environments. References to developmental and emotional damages caused by exposure to community violence, although increasing in number, are still scarce in the literature. Ward et al. specifically addressed the issue of exposure to urban violence in Cape Town. ${ }^{13}$ These authors assessed students from private high schools, and verified that $81.7 \%$ of them had witnessed incidents of violence involving strangers, $30 \%$ had suffered violence from strangers and $71.1 \%$ had suffered violence from people they knew. Exposure to community violence was associated with symptoms of post-traumatic stress disorder and depression in that study.

Our study did not find an association between loss events in childhood and adult mood disorders. This association was not found by Mireault, Bond ${ }^{17}$ or Furukawa et al. ${ }^{33}$ However, most studies were able to detect an association between loss events and depression. 6,15-16 It is important to note that loss events in childhood were very prevalent even in our control group (40\%), probably reflecting the poor background of families in populations of developing countries. This high prevalence of loss events in the control group hampers to detect significant differences between groups.

Our findings must be understood within the context of certain limitations. Since this is a retrospective study, it was not possible to assess the temporal relationship between exposure to trauma and the onset of depressive or manic symptoms, in order to establish a causal relationship between them. However, due to the scarcity of previous studies conducted on this issue in developing countries, cross-sectional investigations may suggest potential risk factors for mood disorders that might be assessed in future prospective studies. The relatively moderate sample size might have determined the lack of power to detect an association between mood disorders and both sexual abuse and loss events in multivariate and bivariate analyses. Furthermore, since this study was conducted with a clinical sample, it is not adequate for inferences about mood disorders in the general population. The design of the study does not protect against a possible memory bias, since the memory accuracy of subjects who were victims of childhood trauma has been questioned. Moreover, depressed adult patients may either have a tendency to distort their recollections, usually to make them worse, or focus more intensely on the negative aspects of events, causing a bias towards an increase of false positives in the findings. ${ }^{34}$ 


\section{Conclusion}

In our study, we were able to detect a higher odds ratio for both exposures to multiple incidents of community violence and childhood/adolescence physical abuse in the group with mood disorders compared to the control group, when these associations were assessed in the context of several potential confounding variables. After subdividing mood disorders, patients with manic episodes were the only group that showed a higher prevalence of exposure to multiple incidents of community violence and childhood physical and sexual abuse than did patients in the control group. Further studies on the association between psychological trauma and mood disorders must be accomplished in developing countries, with a more comprehensive perspective beyond the traditional individual focus usually employed in the clinical practice and even in medical research.

\section{Acknowledgements}

Joy Osofsky PhD, for the incentive to conduct this study; Viviane Oliveira PhD and Sílvia Benetti, for their careful revision.

\section{References}

1. Blazer II DG. Mood disorders epidemiology. In: Kaplan HI, Sadock BJ, eds. Comprehensive Textbook of Psychiatry. 7th ed. Baltimore, MD: Lippincott Williams and Wilkins; 2000. p. 1298-308.

2. OMS. Informe sobre la salud en el mundo. Salud mental: nuevos conocimientos, nuevas esperanzas. Organización Mundial de la Salud: Ginebra; 2001.

3. Almeida-Filho N, Mari J de J, Coutinho E, Franca JF, Fernandes J, Andreoli SB, Busnello ED. Brazilian multicentric study of psychiatric morbidity. Methodological features and prevalence estimates. $\mathrm{Br} \mathrm{J}$ Psychiatry. 1997;171:524-9.

4. Kendler KS, Bulik CM, Silberg J, Hettema, JM, Myers J, Prescott CA. Childhood sexual abuse and adult psychiatric and substance use disorders in women: an epidemiological and cotwin control analysis. Arch Gen Psychiatry. 2000;57(10):953-9.

5. Akiskal HS. Mood disorders: introduction and overview. In: Kaplan HI, Sadock BJ, eds. Comprehensive Textbook of Psychiatry. 7th ed. Baltimore, MD: Lippincott Williams and Wilkins; 2000. p. 1284-98.

6. Kessler RC, Davis CG, Kendler KS. Childhood adversity and adult psychiatric disorder in the US National Comorbidity Survey. Psychol Med. 1997;27(5):1101-19.

7. Hall LA, Sachs B, Rayens MK, Lutenbacher M. Childhood physical and sexual abuse: their relationship with depressive symptoms in adulthood. Image J Nurs Sch. 1993;25(4):317-23.

8. Levitan RD, Parikh SV, Lesage AD, Hegadoren KM, Adams M, Kennedy SH, Goering PN. Major depression in individuals with a history of childhood physical or sexual abuse: relationship to neurovegetative features, manic, and gender. Am J Psychiatry. 1998; 155(12):1746-52.

9. Wise LA, Zierler S, Krieger N, Harlow BL. Adult onset of major depressive disorder in relation to early life violent victimisation: a case-control study. Lancet. 2001;358(9285):881-7.

10. Benedict MI, Paine LL, Paine LA, Brandt D, Stallings R. The association of childhood sexual abuse with depressive symptoms during pregnancy, and selected pregnancy outcomes. Child Abuse Negl. 1999;23(7):659-70.

11. Putnam FW. Ten-year research update review: child sexual abuse. J Am Acad Child Adolesc Psychiatry. 2003;42(3):269-78.

12. Hyun M, Friedman SD, Dunner DL. Relationship of childhood physical and sexual abuse to adult bipolar disorder. Bipolar Dis. 2000;2(2):131-5.

13. Ward CL, Flisher AJ, Zissis C, Muller M, Lombard C. Exposure to violence and its relationship to psychopathology in adolescents. Inj Prev. 2001;7(4):297-301.
14. Singer MI, Anglin TM, Song LY, Lunghofer L. Adolescents' exposure to violence and associated symptoms of psychological trauma. JAMA. 1995;273(6):477-82.

15. Amato PR. Parental absence during childhood and depression in later life. Sociol Q. 1991;32(4):543-56.

16. Patten SB. The loss of a parent during childhood as a risk factor for depression. Can J Psychiatry.1991;36(10):706-11.

17. Mireault GC, Bond LA. Parental death in childhood: perceived vulnerability, and adult depression and anxiety. Am J Orthopsychiatry. 1992;62(4):517-24.

18. OMS. Informe mundial sobre la violencia y la salud. Ginebra: Organización Mundial de la Salud; 2002.

19. American Psychiatric Association. DSM-IV. Diagnostic and statistical manual of mental disorders. 4th ed. Washington, DC: American Psychiatric Association; 1994.

20. Sheehan D, Lecrubier Y, Sheehan KH, Janavs J, Weiller E, Keskiner A, Schinka J, Knapp E, Sheehan MF, Dunbar GC. The validity of the mini international neuropsychiatric interview (MINI) according to the SCID-P and reliability. Eur Psychiatry. 1997;12:232-41.

21. Amorim P. Mini International Neuropsychiatric Interview (MINI): validação de entrevista breve para diagnóstico de transtornos mentais. Rev Bras Psiquiatr. 2000;22(3):106-15.

22. Landis JR, Koch GG. The measurement of observer agreement for categorical data. Biometrics. 1977;33(1):159-74.

23. Wechsler D. Escala de inteligência Wechsler para adultos WAIS-III. Tradução Elizabeth do Nascimento. São Paulo: Casa do Psicólogo; 1996.

24. Ogata SN, Silk KR, Goodrich S, Lohr NE, Westen D, Hill EM. Childhood sexual and physical abuse in adult patients with borderline personality disorder. Am J Psychiatr. 1990;147(8): 1008-13.

25. Richters JE, Martinez P. The NIMH Community Violence Project: I. Children as victims of and witnesses to violence. Psychiatry. 1993;56(1):7-21.

26. Osofsky JD. The effects of exposure to violence on young children. Am Psychol. 1995;50(9):782-8.

27. Richters JE, Saltzman W. Survey of exposure to community violence: self-report version. Rockville, MD: National Institute of Mental Health; 1990.

28. Fráguas Jr R, Figueiró JA. Depressões secundárias: peculiaridades da depressão no contexto médico não psiquiátrico. In: Depressões em medicina interna e outras condições médicas. Atheneu: São Paulo; 2001. p. 3-9.

29. Machado S, Abreu P, Pechansky F, Schneider F, Alberti V, Gus G. Depressão em hospital geral II: habilidade de detecção de sintomas depressivos pelo especialista não psiquiatra. Rev $A B P-A P A L$. 1989;11:97-110.

30. Tognola JN, Racz NS. Mujeres sobrepasadas, el drama médico-social de las jefas de hogar politraumatizadas desde la infancia: revisión clínica de 256 casos. Rev Psiquiatr (Chile). 1999;4:221-9.

31. Frias-Armenta M. Long-term effects of child punishment of Mexican women: a structural model. Child Abuse Neg/. 2002;26(4):371-86.

32. Christensen EM, Gjerris A, Larsen JK, Bendtsen BB, Larsen BH, Rolff $H$, Ring G, Schaumburg E. Life events and onset of a new phase in bipolar affective disorder. Bipolar Disord. 2 003;5(5):356-61.

33. Furukawa TA, Ogura A, Hirai T, Fujihara S, Kitamura T, Takahashi K. Early parental separation experiences among patients with bipolar disorder and major depression: a case-control study. J Affect Disord. 1999;52(1-3):85-91.

34. Mechanic MB, Resick PA, Griffin MG. A comparison of normal forgetting, psychopathology, and information processing models of reported amnesia for recent sexual trauma. J Consult Clin Psychol. 1998;66(6):948-57. 